\title{
Glycine Protects Muscle Cells From Wasting in vitro via mTORC1 Signaling
}

\author{
Marissa K. Caldow, Daniel J. Ham ${ }^{\dagger}$, Jennifer Trieu, Jin Dylan Chung, Gordon S. Lynch and \\ René Koopman*
}

Centre for Muscle Research, Department of Physiology, The University of Melbourne, Melbourne, VIC, Australia

OPEN ACCESS

Edited by:

Andrew Philp,

Garvan Institute of Medical

Research, Australia

Reviewed by:

Suzanne Maria Hurst,

The New Zealand Institute for Plant \&

Food Research Ltd, New Zealand

Chris McGlory,

Queen's University, Canada

*Correspondence:

René Koopman

rkoopman@unimelb.edu.au

${ }^{\dagger}$ Present address:

Daniel J. Ham,

The Center for Molecular Life

Sciences, Biozentrum University of

Basel, Basel, Switzerland

Specialty section:

This article was submitted to

Sport and Exercise Nutrition,

a section of the journal

Frontiers in Nutrition

Received: 12 July 2019

Accepted: 25 October 2019

Published: 13 November 2019

Citation:

Caldow MK, Ham DJ, Trieu J, Chung JD, Lynch GS and Koopman R

(2019) Glycine Protects Muscle Cells

From Wasting in vitro via mTORC1

Signaling. Front. Nutr. 6:172.

doi: 10.3389/fnut.2019.00172
Glycine supplementation can protect skeletal muscles of mice from cancer-induced wasting, but the mechanisms underlying this protection are not well-understood. The aim of this study was to determine whether exogenous glycine directly protects skeletal muscle cells from wasting. C2C12 muscle cells were exposed to non-inflammatory catabolic stimuli via two models: serum withdrawal (SF) for $48 \mathrm{~h}$; or incubation in HEPES buffered saline (HBS) for up to $5 \mathrm{~h}$. Cells were supplemented with glycine or equimolar concentrations of L-alanine. SF- and HBS-treated myotubes (with or without L-alanine) were $\sim 20 \%$ and $\sim 30 \%$ smaller than control myotubes. Glycine-treated myotubes were up to $20 \%$ larger $(P<0.01)$ compared to cells treated with $L$-alanine in both models of muscle cell atrophy. The mTORC1 inhibitor rapamycin prevented the glycine-stimulated protection of myotube diameter, and glycine-stimulated S6 phosphorylation, suggesting that mTORC1 signaling may be necessary for glycine's protective effects in vitro. Increasing glycine availability may be beneficial for muscle wasting conditions associated with inadequate nutrient intake.

Keywords: atrophy, amino acids, muscle wasting, starvation, $\mathrm{C2C12}$, protein synthesis

\section{INTRODUCTION}

The non-essential amino acid glycine is often considered biologically neutral, and not required for the regulation of protein synthesis under normal healthy conditions. However, reduced intracellular levels of glycine have been reported in older individuals (1) and in mouse models of diabetes and muscular dystrophy $(2,3)$, suggesting that either glycine metabolism is increased during these conditions, or tissue demand exceeds dietary intake. Our observations in several mouse models of muscle wasting showed that supplementation with glycine preserved muscle mass and metabolic function in a range of conditions where the anabolic response to nutrition was altered (4-6). Glycine administration attenuated skeletal muscle wasting and loss of physical function in a mouse model of cancer cachexia, which was associated with a reduction in protein breakdown and skeletal muscle markers of inflammation and ROS (4). In a mouse model of acute (LPS-induced) inflammation, glycine administration preserved the skeletal muscle anabolic response to leucine, through upregulation of $\mathrm{MTORC1}$ signaling and preservation of protein 
synthesis. Glycine can affect cell homeostasis via glycine receptor mediated signaling and via its metabolism (7). Indeed, previous reports have linked glycine receptor-mediated signaling, via its scaffolding protein gephyrin, to mTORC1 activation in other tissues (8). In the in vivo LPS model we also showed a reduction in oxidative stress (DHE) but not mRNA expression of proinflammatory cytokines and chemokines in skeletal muscle (6). Dietary glycine supplementation in a mouse model of caloric restriction reduced adiposity (whole-body and epididymal fat mass) and preserved lean mass and muscle mass (5). Together, these data revealed a positive effect of glycine treatment on skeletal muscle protein metabolism, mass and function during muscle wasting conditions. However, it is currently unclear whether the beneficial effects of glycine on skeletal muscle are entirely the result of inflammatory cell inactivation, or whether glycine has muscle cell-specific effects. We tested the hypothesis that glycine would directly attenuate myotube wasting in an mTORC1-dependent manner.

We aimed to determine whether exogenous glycine protects muscle cells from cachectic stimuli. To investigate the effect of glycine on myotube wasting mature $\mathrm{C} 2 \mathrm{C} 12$ myotubes were supplemented with glycine or equimolar concentrations of Lalanine and atrophy induced via 2 different approaches: serum withdrawal for $48 \mathrm{~h}$; or incubation in HEPES buffered saline for up to $5 \mathrm{~h}$.

\section{METHODS Cell Culture}

Murine C2C12 myoblasts (Cryosite distribution, NSW, Australia) were cultured in DMEM (Life Technologies, Australia) containing $10 \%(\mathrm{v} / \mathrm{v})$ fetal calf serum (Life Technologies), $1 \%$ L-glutamine (v/v) (Life Technologies), and 1\% (v/v) antibiotic solution (100 unit/ml penicillin/streptomycin, Life Technologies) at $37^{\circ} \mathrm{C}$ in an atmosphere of $5 \% \mathrm{CO}_{2}$. Upon confluency, the media was changed to differentiation media [DMEM containing $2 \%(\mathrm{v} / \mathrm{v})$ horse serum, $1 \% \mathrm{~L}$-glutamine and $1 \%$ antibiotic solution (Life Technologies)] for 5 days to promote formation of mature multinucleated myotubes (9).

\section{Wasting Conditions}

To induce wasting via growth factor deprivation, cells were washed once in serum free DMEM (Life Technologies, Australia) and then incubated in DMEM (i.e., standard amino acid composition) containing $1 \%$ L-glutamine and $1 \%$ antibiotic solution (Life Technologies) but lacking 2\% horse serum for $48 \mathrm{~h}$ (SF) (9). SF was supplemented with an additional $2.5 \mathrm{mM}$ glycine (Sigma-Aldrich, Castle Hill, NSW, Australia) or L-alanine (Sigma-Aldrich). To induce wasting via nutrient starvation, cells were washed once in HEPES buffered saline (HBS; $20 \mathrm{mM}$ HEPES/Na pH 7.4, $140 \mathrm{mM} \mathrm{NaCl}, 2.5 \mathrm{mM} \mathrm{MgSO}_{4}, 5 \mathrm{mM} \mathrm{KCl}$, and $1 \mathrm{mM} \mathrm{CaCl}_{2}$, no amino acids present), then incubated in $\mathrm{HBS}$ $(9,10)$ with glycine or equimolar concentrations of L-alanine for up to $5 \mathrm{~h}$. L-alanine serves as an isonitrogenous control as it does not modulate cell size and protein turnover in cell and animal models $(4-6,9,10)$.
Rapamycin (100 nM, Sigma-Aldrich) was used to inhibit mTORC1 activation (10). We have previously reported that these atrophy models are not associated with altered myotube viability as assessed by Trypan Blue staining (9).

\section{Glycine Withdrawal}

DMEM media was formulated without glycine (Life Technologies). Basal levels $(0.4 \mathrm{mM})$ or additional amounts $(2.5 \mathrm{mM})$ of glycine (Sigma-Aldrich) were added when appropriate to serum free or differentiation media, as specified.

\section{Myotube Diameter}

Cells were washed $2 \times 5 \mathrm{~min}$ in phosphate buffered saline (PBS) and then fixed with $4 \%$ paraformaldehyde/PBS for $15 \mathrm{~min}$. Cells were then washed in PBS $(3 \times 5 \mathrm{~min})$, permeated with $0.1 \%$ TritonX-100/PBS, washed in PBS $(3 \times 5 \mathrm{~min})$ and then incubated in $3 \%$ bovine serum albumin (BSA)/PBS for $2 \mathrm{~h}$. Cells were incubated with primary antibody overnight at $4^{\circ} \mathrm{C}$. MF20 (1:50; Developmental Studies Hybridoma Bank, University of Iowa, Department of Biology, Iowa City, IA, USA) in 3\% BSA/PBS was used to stain myosin heavy chain (MHC). Cells were then washed with $\mathrm{PBS}(3 \times 5 \mathrm{~min})$ and incubated in goat-anti-mouse IgG2b Alexa555 secondary antibody (1:500, Life Technologies) and DAPI $(1: 1,000)$ for $2 \mathrm{~h}$ in $3 \%$ BSA/PBS. Cells were washed in PBS $(3 \times 5 \mathrm{~min})$ and then imaged on a Zeiss Axiovert $40 \mathrm{CFL}$ inverted microscope using a $10 \mathrm{X}$ objective. Four images were taken in each well from pre-defined locations within each quadrant. Myotube diameter was measured using AxioVision software (AxioVision AC Rel. 4.8.2, Carl Zeiss Imaging Solutions, Wrek, Göttingen; Germany). A total of 50-80 myotubes were measured per well and the average diameter of each well was used for statistical analysis as described previously $(6,9,10)$.

\section{Protein Synthesis}

Myotubes were grown and treated as described previously. To determine the rate of protein synthesis we utilized SUnSET methodology, as described $(10,11)$. Briefly, puromycin (SigmaAldrich) was administered to the media at a final concentration of $1 \mu \mathrm{M}$ exactly $30 \mathrm{~min}$ before cells were collected in icecold homogenizing buffer. Anti-puromycin was purchased from Millipore (Kilsyth, Victoria, Australia) and immunoblotting was used to detect changes in puromycin incorporation as described $(9,10)$.

\section{Protein Extraction and Immunoblotting}

Cell lysates were prepared using RIPA lysis buffer (Merck Millipore, VIC, Australia) including protease and phosphatase inhibitor cocktails (Sigma-Aldrich). Lysates were rotated end over end at $4^{\circ} \mathrm{C}$ for $30 \mathrm{~min}$, then centrifuged at 13,000 $\mathrm{RPM}$ at $4^{\circ} \mathrm{C}$ for $10 \mathrm{~min}$ to collect the supernatant. Protein content was determined via Bio-Rad DC protein assay as per manufacturer's instructions (Bio-Rad Laboratories, NSW, Australia). Briefly, samples were separated by SDS-PAGE using Criterion $^{\mathrm{TM}}$ TGX Stain-Free ${ }^{\mathrm{TM}}$ Precast Gels (Bio-Rad) and proteins were transferred to $0.45 \mathrm{~mm}$ PVDF via Trans-Blot ${ }^{\circledR}$ Turbo $^{\mathrm{TM}}$ transfer system (Bio-Rad). Gels were visualized using 
a ChemiDoc ${ }^{\mathrm{TM}}$ imaging system (Bio-Rad) and images were captured prior to and following transfer. Membranes were blocked for $2 \mathrm{~h}$ at room temperature (RT) in 5\% (w/v) bovine serum albumin (BSA, Sigma-Aldrich) or 5\% Skim Milk (for puromycin) in Tris-buffered saline-Tween 20 (TBST). Membranes were incubated overnight at $4^{\circ} \mathrm{C}$ with primary antibodies. The following day membranes were incubated for $1 \mathrm{~h}$ at RT in horseradish peroxidise-conjugated secondary antibodies. Membranes were treated with enhanced chemiluminescence (Super Signal West Femto; Thermo Scientific) and proteins were visualized using ChemiDoc ${ }^{\mathrm{TM}}$ imaging system (Bio-Rad). Blots were quantified using ImageLab ${ }^{\circledR}$ software (Bio-Rad), and normalized to total protein as quantified from the Stain Free Gel imaging (Figure 3) or by BLOT FastStain ${ }^{\mathrm{TM}}$ as per manufacturer's instructions (G-Biosciences, St. Louis, MO; Figure 2).

\section{Antibodies}

pAkt (S473), Akt, pmTOR (S2448), mTOR, pp70S6K (Thr389), p70S6K, pS6 (S235/236), S6, p4EBP1 (T37/46), 4EBP1, pSTAT3 (Tyr705), and STAT3 were purchased from Cell Signaling Technologies (Beverly, MA, USA) and diluted $1: 1,000$ in 5\% BSA/TBST. Secondary antibodies (donkey anti-rabbit HRP immunoglobulins, GE Healthcare Life Sciences, Australia) were diluted in 5\% BSA/TBST.

To assess whether protein expression of key structural protein were affected by glycine in the wasting models, MF20 (Developmental Studies Hybridoma Bank) was diluted 1:50 in $5 \%$ BSA/TBST. $\alpha$-actin (Sigma-Aldrich) was diluted 1/3,000 in $5 \%$ BSA/TBST. Secondary antibodies (sheep anti-mouse HRP immunoglobulins GE Healthcare Life Sciences) were diluted in 5\% BSA/TBST.

Anti-puromycin (Clone 12D10; Millipore) was diluted 1:5,000 in $1 \% \mathrm{BSA} / \mathrm{TBST}$. Secondary antibodies (goat anti-mouse IgG Fc 2a, Jackson ImmunoResearch Laboratories Inc., West Grove, PA, USA) were diluted 1:50,000 in 5\% milk/TBST.

\section{Statistics}

All values were expressed as mean \pm SD. Data were normalized to the appropriate control group for ease of visualization, unless otherwise stated. Two-way ANOVAs (time and treatment) were used to compare between groups for dose-response, time-course, and rapamycin experiment, while one-way ANOVAs were used for all other comparisons. Tukey's post hoc test was used to determine significant differences between individual groups and $P$ values reported in figures. For transparency, we report both significant differences $(P<0.05)$ and trends $(P<0.1)$ are reported where appropriate.

\section{RESULTS}

\section{Glycine Reduces Muscle Wasting in a Dose-Dependent Manner During Growth Factor Deprivation}

Growth factor deprivation $(48 \mathrm{~h})$ significantly reduced myotube diameter (SF, $-13 \%$; $P<0.05$; Figure 1A). The addition of glycine to SF media attenuated muscle wasting in a dosedependent manner, reaching significance at a concentration of $0.5,1$, and $2.5 \mathrm{mM}$. Importantly, equimolar concentrations of L-alanine did not attenuate myotube wasting, compared to SF alone. Serum starved glycine-treated myotubes were larger (0.5 mM, 18\%; $1 \mathrm{mM}, 16 \% ; 2.5 \mathrm{mM}, 22 \% ; P<0.01)$ compared with SF containing L-alanine-treated myotubes ( $\left.\mathrm{SF} \mathrm{ALA}^{+}\right)$. We have not further investigated why the beneficial effects of glycine were lost at a concentration of $5 \mathrm{mM}$ as we used the doseresponse studies to select the most appropriate and effective dose. All further experiments in SFM were performed using $2.5 \mathrm{mM}$ glycine or L-alanine.

We also removed glycine from SF to determine if basal glycine contributed to any effects on myotube diameter. The removal of glycine $(0.4 \mathrm{mM})$ from SF $\left(\mathrm{SF} \mathrm{GLY}^{-}\right)$did not augment the effects of SF alone (Figure 1B).

\section{Glycine Is Important for Myotube Size Under Normal Growth Conditions}

Removal of glycine from DM $(48 \mathrm{~h})$ induced myotube wasting similar to that caused by nutrient deprivation (SF). Differentiation media without basal glycine reduced myotube diameter by $17 \%$ compared to DM $(P<0.001$; Figure 1C).

\section{Glycine Reduces Muscle Wasting in a Dose-Dependent Manner During Nutrient Starvation}

Nutrient starvation $(5 \mathrm{~h})$ reduced myotube diameter (HBS, $-29 \% ; P<0.05$; Figure 2A). The addition of glycine to HBS attenuated muscle wasting in a dose-dependent manner, reaching significance at a concentration of 1 and $2.5 \mathrm{mM}$. Importantly, equimolar concentrations of L-alanine did not increase myotube diameter, compared to HBS alone. Nutrient deprived (HBS) glycine-treated myotubes were larger $(1 \mathrm{mM}, 18 \% ; 2.5 \mathrm{mM} 14 \% ; P<0.01)$ than myotubes treated with L-alanine ( $\left.\mathrm{HBS} \mathrm{ALA}^{+}\right)$. The beneficial effects of glycine were lost at a concentration of $5 \mathrm{mM}$. All further experiments in HBS were performed using $2.5 \mathrm{mM}$ glycine or L-alanine.

\section{Glycine Maintains Protein Synthesis During Nutrient Starvation}

Protein synthesis was improved by the presence of $2.5 \mathrm{mM}$ glycine during $4 \mathrm{~h}$ of nutrient starvation. At each time point, puromycin incorporation was greater in glycine treated cells, compared to L-alanine treated cells $(P$ $<0.01$, Figure 2B)

\section{Glycine Protects From Muscle Wasting During Nutrient Starvation and Growth Factor Deprivation via mTORC1}

Myotubes were incubated with the mTORC1 inhibitor rapamycin to determine the involvement of mTORC1 in the protective effect of glycine in the nutrient starvation and growth factor deprivation models. We measured the effects of rapamycin on myotube diameter and the phosphorylation 


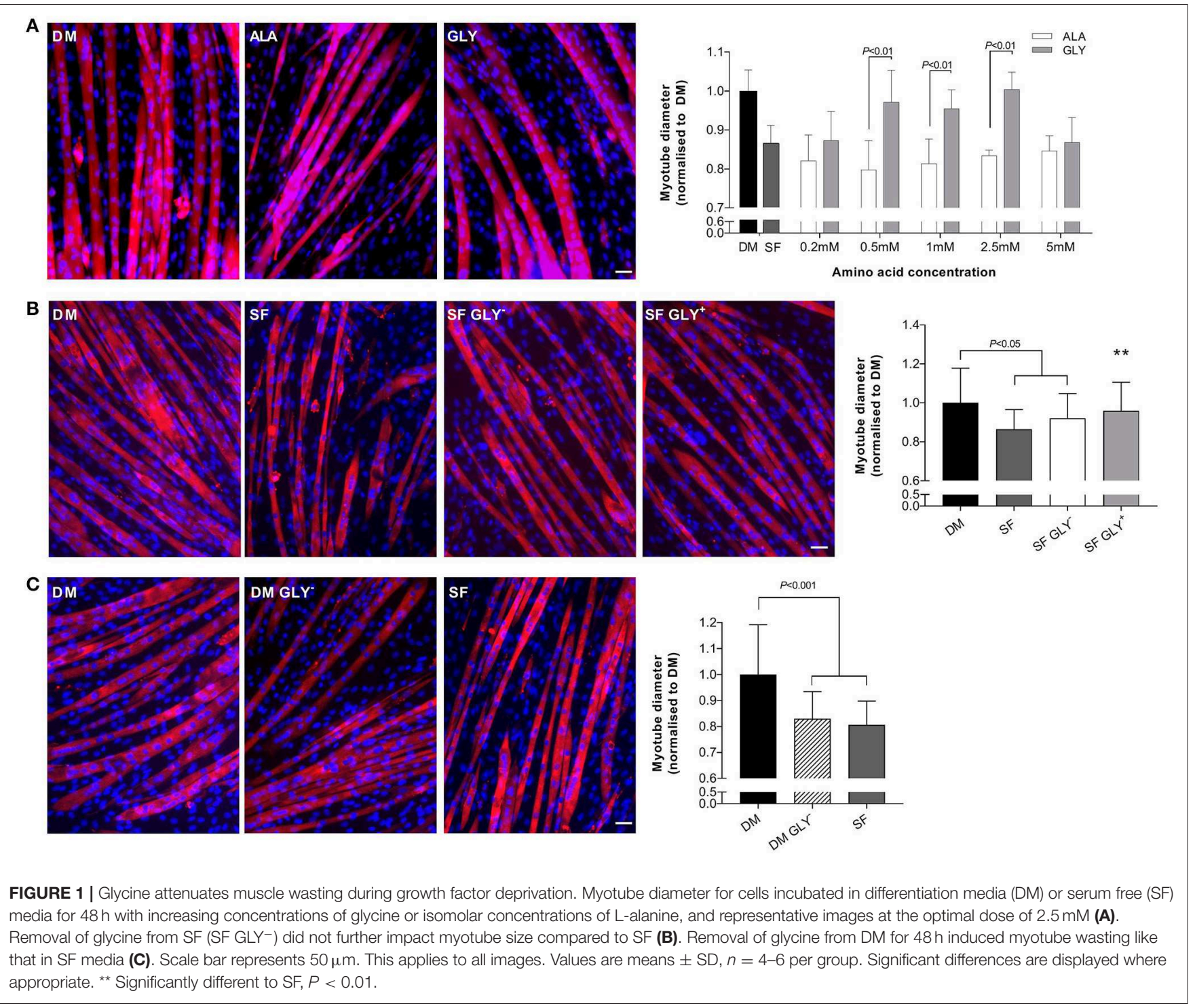

status of downstream targets of mTORC1. In a model of $4 \mathrm{~h}$ nutrient starvation (HBS), rapamycin attenuated the protective effects of glycine by $13 \%(P<0.01)$. There were no significant effects of rapamycin on myotube diameter in L-alanine treated cells (Figure 3A). Rapamycin also prevented the glycine-induced S6 phosphorylation $(P<$ 0.001 , Figure 3C). Similarly, when cells were treated acutely with amino acids and rapamycin in the growth factor deprivation model $(4 \mathrm{~h}, \mathrm{SF})$, rapamycin prevented the maintenance of S6 phosphorylation $(P<0.001$, Figure 3E). In L-alaninetreated cells, rapamycin also reduced S6 phosphorylation in both the deprivation ( $4 \mathrm{~h}$ HBS, $P<0.05$ ) and starvation models (4h SF, $P<0.01$ ). No changes in AKT, mTOR, p70S6K or 4EBP1 phosphorylation were observed under any treatment condition (Figures 3B,D). Similarly, there were no changes in pSTAT3 phosphorylation or MF20 and $\alpha$-actin protein abundance between the treatment groups (Supplementary Figure 1).

\section{DISCUSSION}

Calorie restriction is a common lifestyle intervention effective in combating obesity and the associated risk of metabolic diseases. Although glycine supplementation helps preserve lean mass in a mouse model of calorie restriction (5), the mechanisms for the protective effect have not been resolved. In the present study, we demonstrated that glycine protects against myotube wasting in an mTORC signaling-dependent manner in two in vitro models of nutrient/growth factor restriction.

Our model of nutrient starvation (HBS) has been shown previously to dramatically reduce protein synthesis and mTORC1 signaling and reduce myotube diameter (10). Similarly, $48 \mathrm{~h}$ of nutrient deprivation (SF) induced myotube atrophy. We observed a dose-dependent protection from myotube wasting in glycine treated $\mathrm{C} 2 \mathrm{C} 12$ cells, in both $\mathrm{HBS}$ and SF models. The applied dose $(2.5 \mathrm{mM})$ of glycine is $\sim 10$-fold higher than basal plasma concentrations, but only $40 \%$ higher than basal 


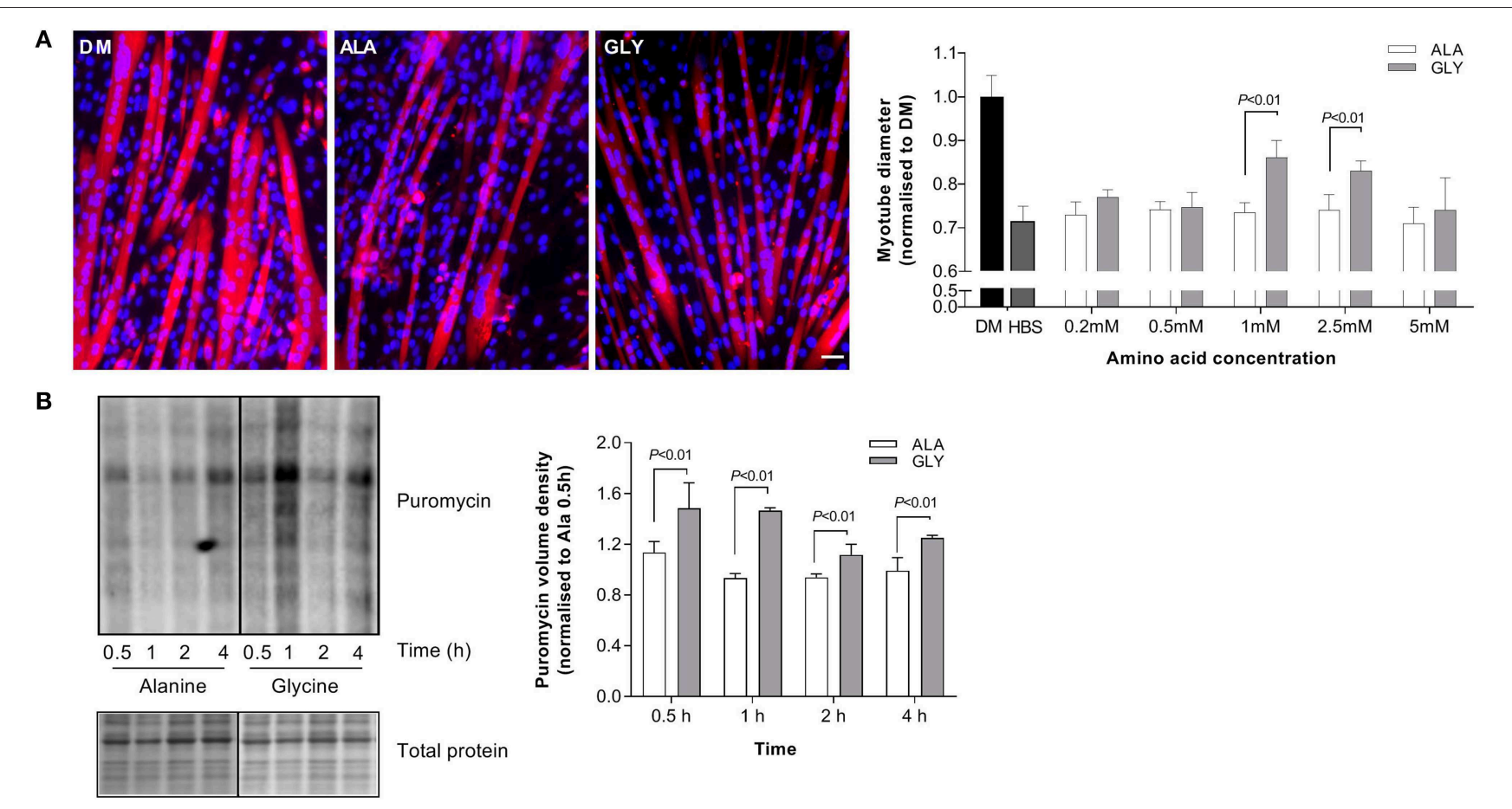

FIGURE 2 | Glycine attenuates muscle wasting and preserves rates of protein synthesis during nutrient starvation. Myotube diameter for cells incubated in differentiation media (DM) or HEPES buffered saline (HBS) for $5 \mathrm{~h}$ with increasing concentrations of glycine or isomolar concentrations of $\mathrm{L}$-alanine, and representative images at the optimal dose of $2.5 \mathrm{mM}$ (A). Glycine supplementation improves protein synthesis as assessed using puromycin after incubation in HBS for up to $4 \mathrm{~h}$ (B). Scale bar represents $50 \mu \mathrm{m}$. This applies to all images. Values are means \pm SD, $n=4-6$ per group. Significant differences are displayed where appropriate.

concentration in muscle and comparable to that seen after ingestion of a protein rich meal (12). Removal of glycine from SF media did not aggravate nutrient deprivation-induced atrophy. Interestingly, removal of glycine from differentiation media for $48 \mathrm{~h}$ induced atrophy, comparable to that of cells incubated in SF media. This may be attributed to a disruption in one-carbon metabolism by the loss of exogenous glycine availability and a subsequent inability to maintain cellular homeostasis $(13,14)$. The observation that glycine did not modulate STAT3 phosphorylation in HBS treated cells is in accordance with our previous studies demonstrating that glycine did not affect LPS-induced increases in cytokine production (6). For these reasons we did not pursue studying inflammatory pathways but focused instead on mTORC1 associated signaling.

In $\mathrm{C} 2 \mathrm{C} 12$ myotubes incubated in HBS, glycine supplementation attenuated myotube wasting, maintained protein synthesis and promoted S6 phosphorylation. In both wasting models, the glycine-induced increases in S6 phosphorylation were completely prevented by rapamycin. Likewise, rapamycin inhibited the glycine-stimulated protection of myotube diameter, indicating that mTORC1 signaling is necessary for glycine's protective effects on myotube size in both growth factor deprivation and nutrient starvation models. These results are consistent with the effect of glycine on $\mathrm{C} 2 \mathrm{C} 12$ myoblasts where acute exposure (30 min $-6 \mathrm{~h}$ ) promoted proliferation, cell viability and protein synthesis in the absence of serum, in an mTORC1-dependent manner (15). However, in myoblasts isolated from neonatal chicks, there was no effect of glycine supplementation on mTOR expression (16). The meaning of these observations is unclear since this study measured mTOR and S6K1 mRNA expression rather than the phosphorylation status of these signaling molecules as a measure of mTOR activity. Importantly for the present study, although rapamycin treatment reduced myotube diameter and S6 phosphorylation in L-alanine and glycine treated myotubes, L-alanine did not provide protection from atrophy during wasting conditions.

Upon activation, mTORC1 phosphorylates and activates two parallel signaling pathways. S6 kinase 1 phosphorylation leads to activation of the ribosomal protein $\mathrm{S6}$, while phosphorylation of the eukaryotic initiation factor $4 \mathrm{E}$ (eIF4E)-binding protein (4EBP1) ultimately allows for the synthesis of new proteins. Despite inhibition of S6 phosphorylation by rapamycin in glycine treated cells, there was no alteration in phosphorylation of mTOR, P70S6K and 4EBP1 in either of the nutritional wasting models after $4 \mathrm{~h}$ of treatment suggesting that upstream signaling occurs earlier. Divergence in signaling between S6 and 4EBP1 has been described previously in glycine treated $\mathrm{C} 2 \mathrm{C} 12$ myoblasts (15), and myotubes treated with other amino acids (10) and the reason for these discrepancies remain to be established.

The way in which many amino acids signal to mTORC1 is still relatively unknown. It is possible glycine may signal to 


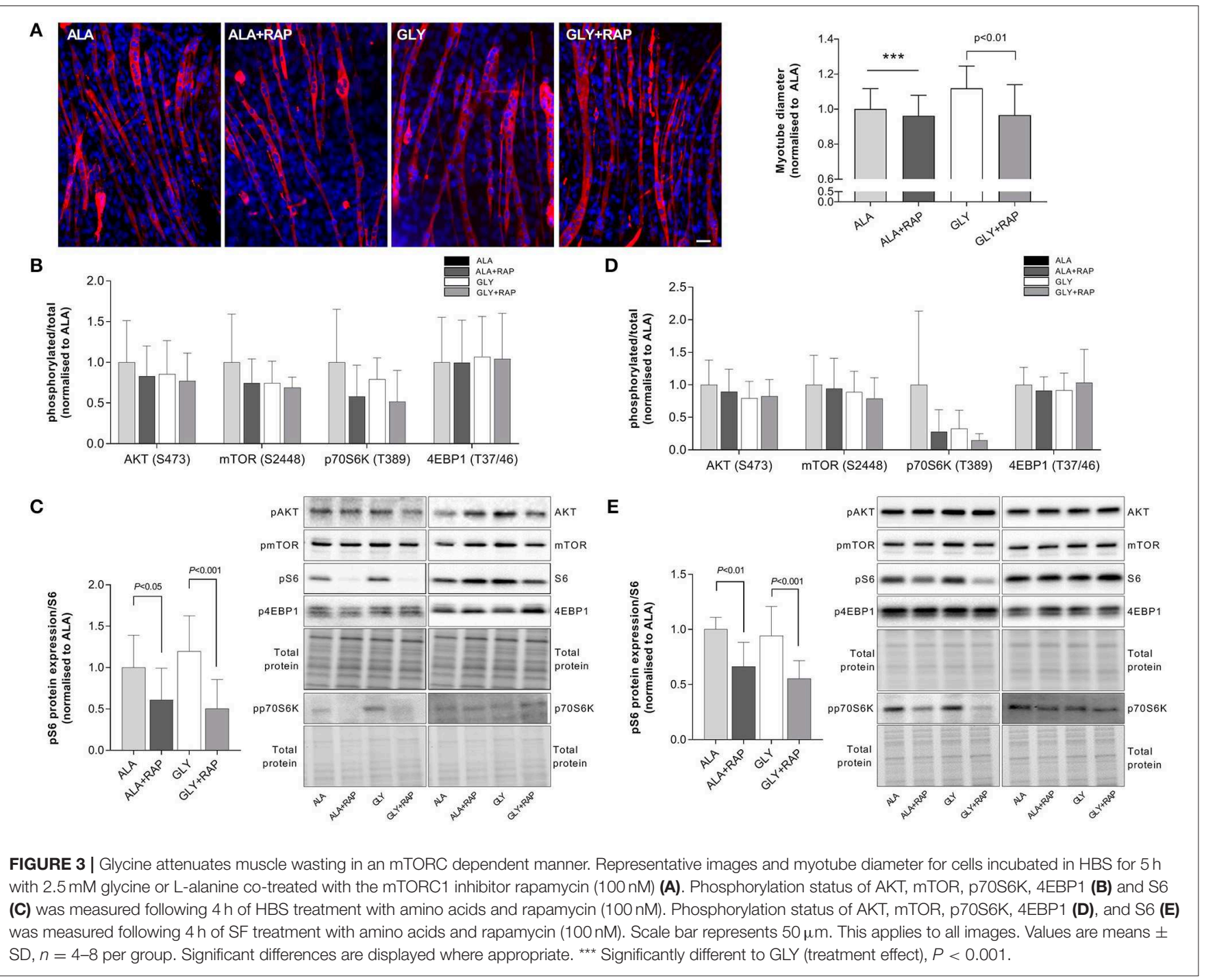

mTORC1 via a non-canonical mechanism using Vps34 (1719). However, it remains to be established whether glycine can mediate Vps34 expression in skeletal muscle. Alternatively, glycine may signal to mTORC1 via its receptor, GlyR (7). GlyRs are inhibitory $\mathrm{Cl}^{-}$channels composed of three different subunits: (1) the ligand binding $\alpha$ subunits (GLRA1, GLRA2, GLRA3, or GLRA4); (2) a structural $\beta$ subunit (GLRB); and (3) a cytoplasmic anchoring protein known as gephyrin (GPHN). GlyR mediated cell-cell communication is enabled by gephyrin, an anchoring protein that provides the scaffolding needed for cytoplasmic GlyR $\beta$ binding (20). Interestingly, it has been suggested gephyrin is required for mTORC1 signaling and contributes to the intracellular localization of mTORC1 and downstream signaling in a variety of cell types $(8,21)$. Although a functional GlyR is still to be identified in skeletal muscle, its presence in cardiac and smooth muscle suggests it is highly likely (22-24). Further studies are required to confirm GlyR-mTORC signaling in skeletal muscle.
In summary our results in $\mathrm{C} 2 \mathrm{C} 12$ myotubes demonstrate a role for glycine in the protection of skeletal muscle wasting in vitro. Rapamycin inhibited the glycine-stimulated protection of myotube diameter, and the glycine-stimulated S6 phosphorylation, indicating that mTORC1 signaling is necessary for glycine's protective effects in vitro. The removal of glycine from differentiation media for $48 \mathrm{~h}$ highlights that glycine is required to maintain cellular homeostasis under normal differentiation conditions. Our results suggest that increasing glycine availability may be beneficial for muscle wasting conditions associated with inadequate nutrient intake.

\section{DATA AVAILABILITY STATEMENT}

The datasets generated for this study are available on request to the corresponding author. 


\section{AUTHOR CONTRIBUTIONS}

MC, DH, GL, and RK interpreted results, conception and design of research, edited and revised manuscript, and approved final version of manuscript. MC, DH, JC, and JT performed experiments. MC and DH analyzed data. MC drafted manuscript.

\section{FUNDING}

MC was supported by a McKenzie Fellowship from the University of Melbourne. DH and MC were funded by an ESPEN Fellowship. This work was supported in part by the National Health and Medical Research Council, Australia (GNT1103571; RK, GL).

\section{REFERENCES}

1. Fazelzadeh P, Hangelbroek RW, Tieland M, de Groot LC, Verdijk $\mathrm{LB}$, van Loon $\mathrm{LJ}$, et al. The muscle metabolome differs between healthy and frail older adults. J Proteome Res. (2016) 15:499-509. doi: 10.1021/acs.jproteome.5b00840

2. Martins-Bach AB, Bloise AC, Vainzof M, Rahnamaye Rabbani S. Metabolic profile of dystrophic mdx mouse muscles analyzed with in vitro magnetic resonance spectroscopy (MRS). Magn Reson Imaging. (2012) 30:1167-76. doi: 10.1016/j.mri.2012.04.003

3. Giesbertz P, Padberg I, Rein D, Ecker J, Hofle AS, Spanier B, et al. Metabolite profiling in plasma and tissues of ob/ob and $\mathrm{db} / \mathrm{db}$ mice identifies novel markers of obesity and type 2 diabetes. Diabetologia. (2015) 58:2133-43. doi: 10.1007/s00125-015-3656-y

4. Ham DJ, Murphy KT, Chee A, Lynch GS, Koopman R. Glycine administration attenuates skeletal muscle wasting in a mouse model of cancer cachexia. Clin Nutr. (2014) 33:448-58. doi: 10.1016/j.clnu.2013.06.013

5. Caldow MK, Ham DJ, Godeassi DP, Chee A, Lynch GS, Koopman R. Glycine supplementation during calorie restriction accelerates fat loss and protects against further muscle loss in obese mice. Clin Nutr. (2015) 35:1118-26. doi: 10.1016/j.clnu.2015.08.013

6. Ham DJ, Caldow MK, Chhen V, Chee A, Wang X, Proud CG, et al. Glycine restores the anabolic response to leucine in a mouse model of acute inflammation. Am J Physiol Endocrinol Metab. (2016) 310:E970-81. doi: 10.1152/ajpendo.00468.2015

7. Koopman R, Caldow MK, Ham DJ, Lynch GS. Glycine metabolism in skeletal muscle: implications for metabolic homeostasis. Curr Opin Clin Nutr Metab Care. (2017) 20:237-42. doi: 10.1097/MCO.00000000000 00383

8. Sabatini DM, Barrow RK, Blackshaw S, Burnett PE, Lai MM, Field ME, et al. Interaction of RAFT1 with gephyrin required for rapamycin-sensitive signaling. Science. (1999) 284:1161-4. doi: 10.1126/science.284.5417.1161

9. Ham DJ, Gleeson BG, Chee A, Baum DM, Caldow MK, Lynch GS, et al. L-Citrulline protects skeletal muscle cells from cachectic stimuli through an iNOS-dependent mechanism. PLoS ONE. (2015) 10:e0141572. doi: 10.1371/journal.pone.0141572

10. Ham DJ, Caldow MK, Lynch GS, Koopman R. Arginine protects muscle cells from wasting in vitro in an mTORC1-dependent and NO-independent manner. Amino Acids. (2014) 46:2643-52. doi: 10.1007/s00726-014-1815-y

11. Goodman CA, Hornberger TA. Measuring protein synthesis with SUnSET: a valid alternative to traditional techniques? Exerc Sport Sci Rev. (2013) 41:107-15. doi: 10.1097/JES.0b013e3182798a95

12. Bergstrom J, Furst P, Vinnars E. Effect of a test meal, without and with protein, on muscle and plasma free amino acids. Clin Sci (Lond). (1990) 79:331-7. doi: 10.1042/cs07 90331

13. Maddocks OD, Berkers CR, Mason SM, Zheng L, Blyth K, Gottlieb E, et al. Serine starvation induces stress and p53-dependent metabolic remodelling in cancer cells. Nature. (2013) 493:542-6. doi: 10.1038/nature11743

\section{ACKNOWLEDGMENTS}

The authors wish to thank Audrey Chan for technical assistance.

\section{SUPPLEMENTARY MATERIAL}

The Supplementary Material for this article can be found online at: https://www.frontiersin.org/articles/10.3389/fnut.2019. 00172/full\#supplementary-material

Supplementary Figure 1 | Phosphorylation of STAT3 and MF20 and $\alpha$-actin protein abundance was measured following $4 \mathrm{~h}$ of HBS (A) or SFM (B) treatment with amino acids and rapamycin $(100 \mathrm{nM})$. Values are means $\pm \mathrm{SD}, n=4$ per group.

14. Maddocks ODK, Athineos D, Cheung EC, Lee P, Zhang T, van den Broek NJF, et al. Modulating the therapeutic response of tumours to dietary serine and glycine starvation. Nature. (2017) 544:372-6. doi: 10.1038/nature22056

15. Sun $\mathrm{K}, \mathrm{Wu} \mathrm{Z}$, Ji Y, Wu G. Glycine regulates protein turnover by activating protein kinase $\mathrm{B} /$ mammalian target of rapamycin and by inhibiting MuRF1 and atrogin-1 gene expression in C2C12 myoblasts. J Nutr. (2016) 146:2461-7. doi: 10.3945/jn.116.231266

16. She Y, Deng H, Cai H, Liu G. Regulation of the expression of key signalling molecules in mTOR pathway of skeletal muscle satellite cells in neonatal chicks: effects of leucine and glycine-leucine peptide. J Anim Physiol Anim Nutr (Berl). (2019) 103:786-90. doi: 10.1111/jpn.13090

17. Nobukuni T, Joaquin M, Roccio M, Dann SG, Kim SY, Gulati P, et al. Amino acids mediate $\mathrm{mTOR} /$ raptor signaling through activation of class 3 phosphatidylinositol 3OH-kinase. Proc Natl Acad Sci USA. (2005) 102:1423843. doi: $10.1073 /$ pnas. 0506925102

18. Nobukuni T, Kozma SC, Thomas G. hvps34, an ancient player, enters a growing game: mTOR Complex1/S6K1 signaling. Curr Opin Cell Biol. (2007) 19:135-41. doi: 10.1016/j.ceb.2007.02.019

19. Yoon MS, Chen J. Distinct amino acid-sensing mTOR pathways regulate skeletal myogenesis. Mol Biol Cell. (2013) 24:3754-63. doi: $10.1091 / \mathrm{mbc}$. e13-06-0353

20. Fritschy JM, Harvey RJ, Schwarz G. Gephyrin: where do we stand, where do we go? Trends Neurosci. (2008) 31:257-64. doi: 10.1016/j.tins.2008.02.006

21. Wuchter J, Beuter S, Treindl F, Herrmann T, Zeck G, Templin MF, et al. A comprehensive small interfering RNA screen identifies signaling pathways required for gephyrin clustering. J Neurosci. (2012) 32:14821-34. doi: 10.1523/JNEUROSCI.1261-12.2012

22. Qi RB, Zhang JY, Lu DX, Wang HD, Wang HH, Li CJ. Glycine receptors contribute to cytoprotection of glycine in myocardial cells. Chin Med J (Engl). (2007) 120:915-21. doi: 10.1097/00029330-200705020-00012

23. Yim PD, Gallos G, Xu D, Zhang Y, Emala CW. Novel expression of a functional glycine receptor chloride channel that attenuates contraction in airway smooth muscle. FASEB J. (2011) 25:1706-17. doi: 10.1096/fj.10-170530

24. Jose Alburquerque-Bejar J, Barba I, Valls-Lacalle L, Ruiz-Meana M, Pecoraro M, Rodriguez-Sinovas A, et al. Remote ischemic conditioning provides humoural cross-species cardioprotection through glycine receptor activation. Cardiovasc Res. (2017) 113:52-60. doi: 10.1093/cvr/cvw242

Conflict of Interest: The authors declare that the research was conducted in the absence of any commercial or financial relationships that could be construed as a potential conflict of interest.

Copyright (๑) 2019 Caldow, Ham, Trieu, Chung, Lynch and Koopman. This is an open-access article distributed under the terms of the Creative Commons Attribution License (CC BY). The use, distribution or reproduction in other forums is permitted, provided the original author(s) and the copyright owner(s) are credited and that the original publication in this journal is cited, in accordance with accepted academic practice. No use, distribution or reproduction is permitted which does not comply with these terms. 